\title{
Article
}

\section{Aromatic Molecules in Restricted Geometries: Pyrene Excimer Formation in an Anchored Bilayer}

L. Mohanambe, and S. Vasudevan

J. Phys. Chem. B, 2006, 110 (29), 14345-14354 • DOI: 10.1021/jp061695e

Downloaded from http://pubs.acs.org on December 2, 2008

\section{More About This Article}

Additional resources and features associated with this article are available within the HTML version:

- $\quad$ Supporting Information

- $\quad$ Links to the 3 articles that cite this article, as of the time of this article download

- Access to high resolution figures

- $\quad$ Links to articles and content related to this article

- $\quad$ Copyright permission to reproduce figures and/or text from this article

\section{View the Full Text HTML}

\section{ACS Publications}




\title{
Aromatic Molecules in Restricted Geometries: Pyrene Excimer Formation in an Anchored Bilayer
}

\author{
L. Mohanambe and S. Vasudevan* \\ Department of Inorganic and Physical Chemistry, Indian Institute of Science, Bangalore 560012, India \\ Received: March 18, 2006; In Final Form: May 25, 2006
}

\begin{abstract}
The galleries of an anionic clay, Mg-Al Layered Double Hydroxide (Mg-Al LDH) have been functionalized by intercalating the anionic surfactant do-decyl sulfate. Within the galleries, the alkyl chains of the surfactant adopt a bilayer structure with the sulfate headgroup anchored to the inorganic sheet. Pyrene molecules have been solubilized in the anchored bilayer by partitioning from polar solvents. The presence of pyrene molecules induces conformational disorder in the alkyl chains of the bilayer and more importantly inhibits the rotational disordering motion of the sulfate headgroup. Pyrene fluorescence indicates formation of excimers whose intensity increases with concentration of solubilized pyrene indicating that they are mobile. Pyrene solubilized in the anchored bilayer exhibits unusual phenomena; on evacuation the excimer band disappear but reappears on releasing vacuum. It is shown that this behavior arises due to the loss of water of hydration of the headgroup on evacuation and as a consequence the pyrene moves into the less polar interior of the bilayer where it is immobile and can no longer diffuse and form excimers. The motion of pyrene into the interior of the bilayer creates free space near the surfactant chain termini, which manifests in the disappearance of the methylrocking mode of the ordered (-tt) end-chain conformer in the Raman spectra.
\end{abstract}

\section{Introduction}

The self-organization of long-chain amphiphilic molecules introduced by intercalation within the galleries of layered inorganic solids provides a novel route for the construction of organic-inorganic supramolecular assemblies. Grafting of longchain surfactant molecules to the walls of the galleries of the solid, to form intercalated anchored bilayers, converts the essentially hydrophilic internal surface of the inorganic solid to one that is hydrophobic and, therefore, capable of adsorbing nonpolar and poorly water-soluble organic molecules, in much the same way as surfactant micelles can solubilize these molecules in aqueous media. In such situations the intercalated surfactant bilayer may be considered as the host or alternatively as a two-dimensional solvent. ${ }^{1}$ Most applications have, indeed, been based on the ability of the intercalated anchored bilayer to solubilize neutral organic molecules within the interlamellar space of an inorganic solid. These hybrid materials have found use as adsorbents for contaminants and pollutants in soil and water remediation. ${ }^{2}$ The intercalated anchored bilayer has also been considered as a membrane mimic $^{3}$ allowing for the incorporation of biomolecules such as cholesterol ${ }^{4}$ within the hydrophobic interior of the bilayer. These hybrid systems have the experimental advantage that unlike lipid bilayers, which are essentially fluidlike, the anchored bilayers are amenable to study by conventional solid-state spectroscopic techniques. Here we have examined the solubilization and excimer formation of pyrene in an anchored surfactant bilayer formed by intercalation of dodecyl sulfate anions in the anionic clay, $\mathrm{Mg}$-Al layered double hydroxide.

Layered double hydroxides (LDHs), the so-called anionic clays, consist of positively charged brucite-like layers and interlamellar exchangeable anions. Hydrotalcites are layered double hydroxides with the chemical composition $\left[\mathrm{Mg}_{1-x} \mathrm{Al}_{x^{-}}\right.$

* To whom correspondence should be addressed. E-mail: svipc@ ipc.iisc.ernet.in. Phone: +91-80-2293-2661. Fax: +91-80-2360-1552/0683.
$\left.(\mathrm{OH})_{2}\right]^{x+}\left[\mathrm{A}_{n}{ }^{-}\right]_{x / n} \cdot m \mathrm{H}_{2} \mathrm{O}(\mathrm{Mg}-\mathrm{Al} \mathrm{LDH})$ that consist of positively charged layers constructed from edge sharing $\mathrm{Mg}(\mathrm{OH})_{6}$ and $\mathrm{Al}(\mathrm{OH})_{6}$ octahedra. $^{5-7}$ The positive charge of the layers is compensated for by interlayer anions that are usually hydrated and can be exchanged for other inorganic or organic anions. The guest species, however, have, out of necessity, to be anions for charge neutrality to be preserved. The host-guest chemistry of the LDHs may be extended to include neutral guest molecules by appropriate functionalization of the gallery walls by intercalation of anionic surfactants,${ }^{8}$ fatty acids, or dervatized cyclodextrins. ${ }^{9}$ Functionalization allows for a variety of neutral nonpolar guest molecules to be included in the interlamellar space of the LDH. In the cyclodextrin functionalized LDH, for example, organometallic guests such as ferrocene, ${ }^{10}$ as well as polyaromatic hydrocarbons, ${ }^{11,12}$ have been included. The inclusion of pyrene and its photochemistry in a fatty acid functionalized LDH has been reported. ${ }^{13}$

Pyrene and its derivatives are among the most extensively used luminescent probes of polarity and microviscosity of organized assemblies such as micelles, ${ }^{14}$ polymers, ${ }^{15}$ metal oxides, ${ }^{16}$ cyclodextrins, ${ }^{17}$ zeolites,${ }^{18}$ sol-gel-derived materials, ${ }^{19}$ monolayers, ${ }^{20}$ and lipid membranes, ${ }^{13}$ as well as surfaces. ${ }^{21}$ Pyrene has several advantages as a probe molecule. Its vibronic structure is known to be sensitive to the polarity of the environment; the ratio of fluorescence intensity of the first to the third vibronic peaks $\left(\mathbf{I}_{\mathrm{I}} / \mathbf{I}_{\mathrm{III}}\right)$ ranges from $\sim 0.6$ in hydrocarbon media to $\sim 2$ in dimethyl sulfoxide. ${ }^{22}$ Additionally, pyrene has the ability to form excimers whose kinetics of formation provide a measure of the local microviscosity. Implicit in the above considerations is the assumption that because of its small size the pyrene probe does not disturb its immediate surroundings so that the polarity and/or microviscosity values are a reflection of the value of the ensemble. ${ }^{23}$

The solubilization and excimer formation of pyrene in a surfactant functionalized $\mathrm{Mg}-\mathrm{Al} \mathrm{LDH}$ is described here. The 
anionic surfactant, dodecyl sulfate $\left(\mathrm{CH}_{3}\left(\mathrm{CH}_{2}\right)_{11} \mathrm{SO}_{4}\right.$, DDS), has been intercalated between $\mathrm{Mg}_{0.63} \mathrm{Al}_{0.37}(\mathrm{OH})_{2}$ sheets. The intercalated surfactant chains are organized as bilayers with the sulfate headgroup anchored to the LDH sheet and the pyrene included within it. Pyrene is poorly adsorbed on the hydrophilic surface of the LDH but is readily adsorbed within the anchored bilayer of the surfactant functionalized $\mathrm{Mg}-\mathrm{Al} \mathrm{LDH}$, just as in the previously reported fatty acid functionalized LDH. Pyrene solubilized in the intercalated anchored bilayer offers the advantage that both the "host", the anchored surfactant bilayer, and the "guest", pyrene, can be probed by spectroscopic techniques. It has, therefore, been possible to examine changes in the conformation of the methylene chains of the anchored bilayer on inclusion of pyrene, as well as probe the effect of chain conformation on the mobility and hence excimer formation of pyrene.

\section{Experimental Section}

Materials and Methods. $\mathrm{Mg}_{1-x} \mathrm{Al}_{x}(\mathrm{OH})_{2}\left(\mathrm{NO}_{3}\right)_{x}[\mathrm{Mg}-\mathrm{Al}$ $\mathrm{LDH}-\mathrm{NO}_{3}$ ] was prepared by coprecipitation by dropwise addition of known volumes of aqueous $\mathrm{Mg}\left(\mathrm{NO}_{3}\right)_{2}(0.04 \mathrm{M})$ and $\mathrm{Al}\left(\mathrm{NO}_{3}\right)_{3}(0.02 \mathrm{M})$ into $\mathrm{NaOH}$ at a constant $\mathrm{pH}$ of 8 , under $\mathrm{N}_{2}$ atmosphere. The resulting white precipitate was aged for $24 \mathrm{~h}$ prior to washing with decarbonated water. Dodecyl sulfate (DDS) surfactant anions were introduced into the galleries of the $\mathrm{Mg}-\mathrm{Al} \mathrm{LDH}$ by ion-exchanging the $\mathrm{NO}_{3}{ }^{-}$ions in $\left[\mathrm{Mg}_{0.63}{ }^{-}\right.$ $\left.\mathrm{Al}_{0.37}(\mathrm{OH})_{2}\left(\mathrm{NO}_{3}\right)_{0.37}\right]\left(\mathrm{Mg}-\mathrm{Al} \mathrm{LDH}-\mathrm{NO}_{3}\right)$ for the surfactant anions, $\left(\mathrm{CH}_{3}\left(\mathrm{CH}_{2}\right)_{11} \mathrm{SO}_{4}\right){ }^{3}$ Ion-exchange of dodecyl sulfate anions was effected by stirring 1 equiv of $\mathrm{Mg}-\mathrm{Al} \mathrm{LDH}-\mathrm{NO}_{3}$ with 2 equiv of sodium dodecyl sulfate (SDS) (Aldrich) for 24 h. The ion-exchanged $\mathrm{Mg}_{0.63} \mathrm{Al}_{0.37}(\mathrm{OH})_{2}(\mathrm{DDS})_{0.37}(\mathrm{Mg}-\mathrm{Al} \mathrm{LDH}-$ DDS) was filtered and washed with water to remove excess SDS. Completion of ion-exchange was ascertained by the absence of $00 l$ reflections due to $\mathrm{Mg}-\mathrm{Al} \mathrm{LDH}-\mathrm{NO}_{3}$ in the X-ray diffraction pattern and the appearance of a new series of $00 l$ reflections with a lattice spacing of $26.2 \AA$ corresponding to the formation of Mg-Al LDH-DDS. The tetradecyl sulfate (TDS) and octadecyl sulfate (ODS) ions were also intercalated by using a similar procedure. All these compounds were prepared for a $\mathrm{Mg} / \mathrm{Al}$ ratio of $x=0.37$ as estimated by using inductively coupled plasma spectrometry. The value of $x$ was independently estimated from the DDS stoichiometry in Mg-Al LDH-DDS, using $\mathrm{CHN}$ analysis.

The solubilization of pyrene in the intercalated surfactant bilayer phase, Mg-Al LDH-DDS, was effected by equilibrating 10-mg quantities of $\mathrm{Mg}$-Al LDH-DDS with $10 \mathrm{~mL}$ of either aqueous $(0.066-0.66 \mu \mathrm{M})$ or $2: 1$ methanol water $(0.03-7.0$ $\mathrm{mM}$ ) solution of pyrene of varying concentrations. Equilibration was carried out at $298 \mathrm{~K}$ and the typical equilibrium time was $48 \mathrm{~h}$. The concentration of the included pyrene was estimated as the difference in concentration of pyrene in the solution before and after equilibration. The concentration of pyrene was estimated spectrophotometrically by monitoring the intensity of the pyrene band at $335 \mathrm{~nm}$. The Beer-Lamberts calibration for the pyrene solutions was verified prior to the adsorption measurements. The concentration of the included pyrene is expressed as the molar ratio of the included pyrene to intercalated DDS ion in the intercalated bilayer phase and is henceforth referred to as the py/DDS ratio.

The concentration of pyrene in the intercalated phase was also determined by using near-infrared Raman spectroscopy. Concentrations were determined from the ratio of the integrated intensity of the $\mathrm{C}-\mathrm{C}$ stretching mode at $1240 \mathrm{~cm}^{-1}$ of pyrene $\mathbf{I}_{1240}$ and the integrated intensity of the $\mathrm{CH}_{2}$ stretching region between 2800 and $3000 \mathrm{~cm}^{-1}, \mathbf{I}_{\mathrm{CH}_{2}}$, in the Raman spectra. These modes have been chosen since their positions remain unchanged from that in the parent compounds and do not suffer from complications arising from overlapping bands. A linear relation of the intensity ratio $\mathbf{I}_{1240} / \mathbf{I}_{\mathrm{CH}_{2}}$ with that of the concentration ratio pyrene/DDS was established by measuring the Raman spectra of physical mixtures of pyrene and sodium dodecyl sulfate (SDS) for different pyrene/SDS molar ratios (Supporting Information). The py/DDS ratio for pyrene included in $\mathrm{Mg}-\mathrm{Al}$ LDH-DDS was determined from the $\mathbf{I}_{1240} / \mathbf{I}_{\mathrm{CH}_{2}}$ ratio in the Raman spectra recorded under identical conditions.

The powder X-ray diffraction pattern of $\mathrm{Mg}-\mathrm{Al} \mathrm{LDH}-\mathrm{NO}_{3}$, Mg-Al LDH-DDS, and Mg-Al LDH-DDS(Pyrene) was recorded on a Shimadzu XD-D1 X-ray diffractometer, using $\mathrm{Cu} \mathrm{K} \alpha$ radiation of $\lambda=1.54 \AA$. The samples were mounted by pressing the powders on a glass plate, and the data were collected at a scan speed of $2^{\circ} 2 \theta / \mathrm{min}$. FT-IR spectra were recorded with $\mathrm{KBr}$ matrix on a Perkin-Elmer SPECTRUM 2000 spectrometer operating at $4 \mathrm{~cm}^{-1}$ resolution. FT-Raman spectra were recorded on a Bruker IFS FT-Raman spectrometer, using an Nd:YAG $(\lambda=1064 \mathrm{~nm})$ laser for excitation. Spectra were recorded at a resolution of $4 \mathrm{~cm}^{-1}$ with an unpolarized beam, using an $\mathrm{Al}$ sample holder. Laser power was kept at $150 \mathrm{~mW}$. $\mathrm{Mg} / \mathrm{Al}$ ratios in the LDH were determined by inductively coupled plasma spectroscopy (Jobin Yvon JY24). CHN analysis was performed on a CHNS (CARLO ERBA) elemental analyzer. Thermogravimetry and evolved gases were recorded on a NETZSCH, TG 209 F1 thermo gravimetric/differential thermal analyzer (TG/ DTA) system coupled with a QMS 403 C Aëolos quadrupole mass spectrometer in flowing air and in a vacuum. Fluorescence spectra were recorded on a Perkin-Elmer LS50B model, with excitation and emission slit widths of 5-10 nm and a scan speed of $60 \mathrm{~nm} / \mathrm{min}$. The fluorescence decay measurements were carried out on an IBH TBX-04 nanosecond flash lamp timeresolved spectrofluorometer. Decay curves were analyzed by using the reconvolution analysis, using a nonlinear least-squares procedure, by means of the DAS6 fluorescence analysis software from IBH.

\section{Results}

The Anchored Bilayer: Dodecyl Sulfate Ions Intercalated in Mg-Al LDH. X-ray diffraction: The X-ray diffraction patterns of dodecyl sulfate (DDS) ions intercalated in $\mathrm{Mg}-\mathrm{Al}$ $\mathrm{LDH}$ along with the parent $\mathrm{Mg}-\mathrm{Al} \mathrm{LDH}-\mathrm{NO}_{3}$ are shown in Figure 1. Only $00 \mathrm{l}$ reflections are observed because of the lamellar morphology of the crystallites. The $00 \mathrm{l}$ reflections correspond to an interlayer spacing of $26.2 \AA$ for $\mathrm{Mg}-\mathrm{Al} \mathrm{LDH}-$ DDS, which is in agreement with the earlier reported value. ${ }^{24}$ The X-ray diffraction patterns of $\mathrm{CH}_{3}\left(\mathrm{CH}_{2}\right)_{n} \mathrm{SO}_{4}$ with $n=13$ (tetradecyl sulfate) and 17 (octadecyl sulfate) were also recorded. The interlayer lattice spacings are 29.2 and $34.1 \AA$, respectively. The variation in $d$ spacing with $n$ (the number of methylene units) is linear with a slope of 1.32 (Figure 1 inset). The lattice expansion on intercalation of the DDS ion is $21.4 \AA$, and the value is longer than the length of the all-trans DDS anion (20.8 $\AA$ ) suggesting that on intercalation the surfactant ions are arranged either in an almost perpendicular partially interdigitated bilayers arrangement or a normal bilayer arrangement with the molecular axis of the surfactant tilted away from the interlayer normal. These two arrangements may be distinguished from the variation of the interlayer spacing with length of the surfactant if the conformation of the alkyl chains of the intercalated DDS anions can be established. 


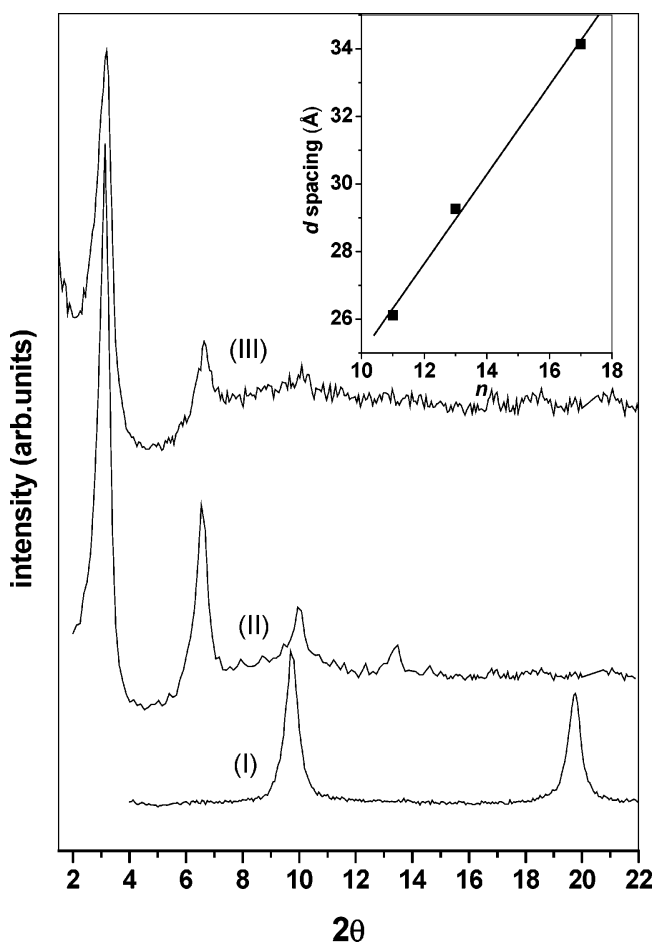

Figure 1. X-ray diffraction patterns for (I) $\mathrm{Mg}-\mathrm{Al} \mathrm{LDH}_{-} \mathrm{NO}_{3}$, (II) $\mathrm{Mg}$ Al LDH-DDS, and (III) Mg-Al LDH-DDS(Pyrene), py/DDS $=0.01$. The inset shows a plot of $d$ spacing vs $n$, the number of methylene units in the surfactant.

Vibrational spectra: Infrared and Raman spectroscopy have been extensively used to probe conformation of alkyl chains. ${ }^{25,26}$ These studies have led to a detailed correlation of the spectra with structural features such as chain conformation, chain packing, and even specific conformational sequences. The position, line-shape, and splitting of the methylene stretching and bending modes have been used to characterize the conformation of methylene chains in alkyl assemblies in systems such as phospholipids ${ }^{25}$ and in intercalated surfactant bilayers in layered solids. ${ }^{8,23}$ The infrared and Raman spectra of the dodecyl sulfate intercalated $\mathrm{Mg}-\mathrm{Al} \mathrm{LDH}$ is similar to that of the crystalline salt, sodium dodecyl sulfate (SDS). The spectra and detailed assignments are provided as part of the Supporting

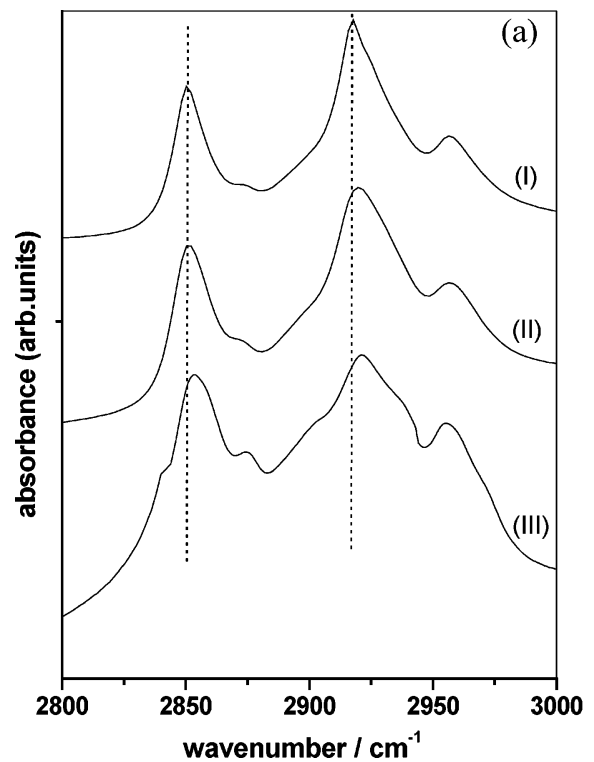

Information. Attention is focused here on the conformationally sensitive methylene stretching modes.

The intense bands at 2850 and $2918 \mathrm{~cm}^{-1}$ in the infrared spectrum of Mg-Al LDH-DDS (Figure 2a) are assigned to the methylene symmetric and antisymmetric stretching modes of the alkyl chains of the intercalated surfactant. These modes are sensitive to the conformation of the methylene chains. For an all-trans alkyl chain, as in the case of crystalline $n$-alkanes, the symmetric and antisymmetric stretching modes of the methylene, $-\left(\mathrm{CH}_{2}\right)_{n^{-}}$, groups appear in the range 2846-2849 and 2916$2918 \mathrm{~cm}^{-1}$, respectively. ${ }^{28}$ With increasing number of gauche conformers, as in the high-temperature disordered liquid phases of $n$-alkanes, the position of these peaks shifts to higher wavenumbers, typically $2856-2858 \mathrm{~cm}^{-1}$ for the symmetric stretching mode and $2924-2928 \mathrm{~cm}^{-1}$ for the antisymmetric stretching mode. ${ }^{29}$ The observed peak positions of the symmetric $\left(2850 \mathrm{~cm}^{-1}\right)$ and antisymmetric $\left(2918 \mathrm{~cm}^{-1}\right) \mathrm{C}-\mathrm{H}$ stretching modes of the methylene groups in $\mathrm{Mg}-\mathrm{Al} \mathrm{LDH-DDS}$ are close to those observed in crystalline SDS as well as $n$-alkanes having predominately all-trans conformation.

The Raman spectrum of the surfactant intercalated $\mathrm{Mg}-\mathrm{Al}$ LDH-DDS is dominated by two prominent bands centered at 2880 and $2850 \mathrm{~cm}^{-1}$ (Figure 2b), which are assigned to the antisymmetric $\left(d^{-}\right)$and symmetric $\left(d^{+}\right)$stretching modes of the methylene units. ${ }^{29}$ The asymmetric stretching mode of the terminal methyl group appears at $2959 \mathrm{~cm}^{-1}$. The ratio of the intensities of the $d^{-}\left(2880 \mathrm{~cm}^{-1}\right)$ to the $d^{+}\left(2850 \mathrm{~cm}^{-1}\right)$ modes $\left(\mathbf{I}_{2880} / \mathbf{I}_{2850}\right)$ is known to be sensitive to both conformational disorder of the alkyl chains as well as their packing and has been widely used to characterize alkyl chain assemblies. ${ }^{25}$ It has been shown that $\mathbf{I}_{2850}$ is sensitive to lateral interactions and hence to the packing arrangement. ${ }^{30,31}$ The intensity $\mathbf{I}_{2880}$ is, however, unaffected by such interactions but is sensitive to the conformation of the methylene chain, decreasing in the liquid phase as compared to the solid. The intensity ratio $\left(\mathbf{I}_{2880} / \mathbf{I}_{2850}\right)$ is, thus, sensitive to both conformational order as well as lateral interactions. The reported values of $\left(\mathbf{I}_{2880} / \mathbf{I}_{2850}\right)$ vary from $\sim 2$ as in crystalline $n$-alkanes to $\sim 0.7$ in the corresponding liquid phase. ${ }^{30}$ The value of the $\mathbf{I}_{2880} / \mathbf{I}_{2850}$ ratio for $\mathrm{Mg}$-Al LDH-DDS is 1.5 while in crystalline SDS it is 1.16 . The lower value of the $\mathbf{I}_{2880} / \mathbf{I}_{2850}$ ratio for crystalline SDS relative to $\mathrm{Mg}-\mathrm{Al} \mathrm{LDH}$ DDS does not indicate that SDS is less ordered as the

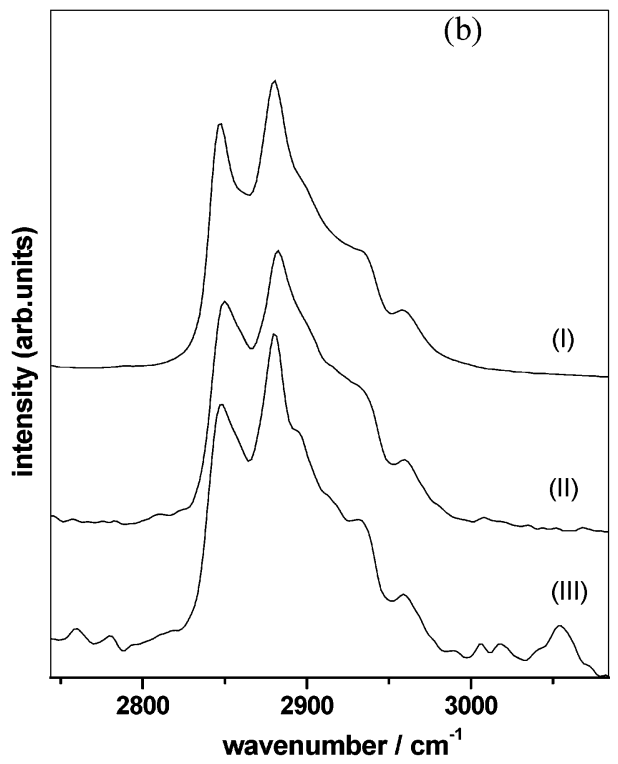

Figure 2. (a) Infrared and (b) Raman spectra of (I) SDS, (II) Mg-Al LDH-DDS, and (III) Mg-Al LDH-DDS(Pyrene) (py/DDS = 0.07). 


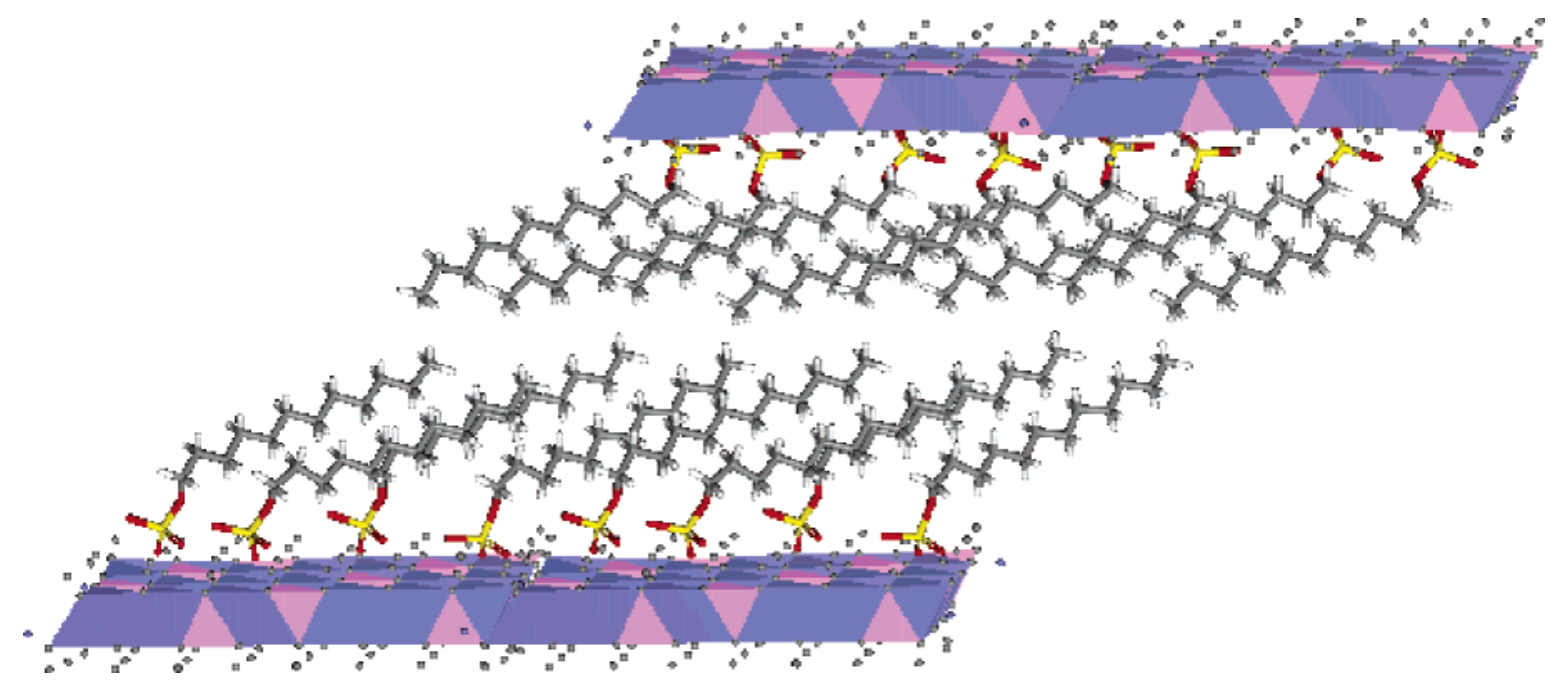

Figure 3. Model representing the tilted bilayer arrangement of alkyl chains in Mg-Al LDH-DDS.

quantitative significance of this ratio is ambiguous by the presence of two influencing factors, packing and conformation.

The infrared and Raman spectra indicate that in the surfactant intercalated bilayer phase of $\mathrm{Mg}-\mathrm{Al} \mathrm{LDH}-\mathrm{DDS}$ the majority of alkyl chains, at this anchoring density, adopt the trans conformation. For an all-trans chain the increment in alkyl chain length with every additional methylene unit is $1.25 \AA$. The observed variation in interlayer spacing with $n$ (the number of methylene units) is linear with a slope of 1.32 (Figure 1 inset). The observed slope can therefore be accounted for by a normal bilayer arrangement with the methylene chain tilted away from the interlamellar normal by an angle of $58^{\circ}$. Such an arrangement is shown in Figure 3.

A notable difference between the bilayers formed in the galleries of the LDH and normal surfactant/lipid bilayers found in aqueous media is that in the intercalated bilayer the negatively charged headgroup of the surfactant is anchored firmly to the positively charged inorganic layer by electrostatic interactions. Lateral mobility of the alkyl chains in these anchored bilayers is, therefore, absent.

Solubilization of Pyrene in the Anchored Bilayer. Adsorption isotherm: Room-temperature isotherms for adsorption of pyrene from aqueous and 2:1 methanol-water solutions of pyrene by Mg-Al LDH-DDS are shown in Figure 4. The amount of pyrene adsorbed by the intercalated surfactant, expressed as the molar ratio of adsorbed pyrene to DDS ions in the intercalated bilayer phase (py/DDS ratio), is plotted as a function of the concentration of pyrene in solution at equilibrium. The plot shows the adsorption isotherms for two different concentration ranges.

The adsorption isotherm does not follow the Langmuir isotherm but instead is linear in both concentration ranges indicating that inclusion of pyrene is by a partitioning process. ${ }^{32}$ The maximum concentration of pyrene that we were able to solubilize in Mg-Al LDH-DDS was from a saturated solution of pyrene in 2:1 methanol-water and corresponds to a py/DDS ratio of 0.07 . It is not possible to partition pyrene into the anchored bilayer from nonpolar solvents such as hexane where the solubility of pyrene is higher.

The solubilization of pyrene in the anchored bilayer occurs with no change in the interlayer spacing, irrespective of the concentration of the solubilized pyrene. The X-ray diffraction pattern of a Mg-Al LDH-DDS(Pyrene) sample with a py/DDS ratio of 0.01 is shown in Figure 1. The Bragg reflections,

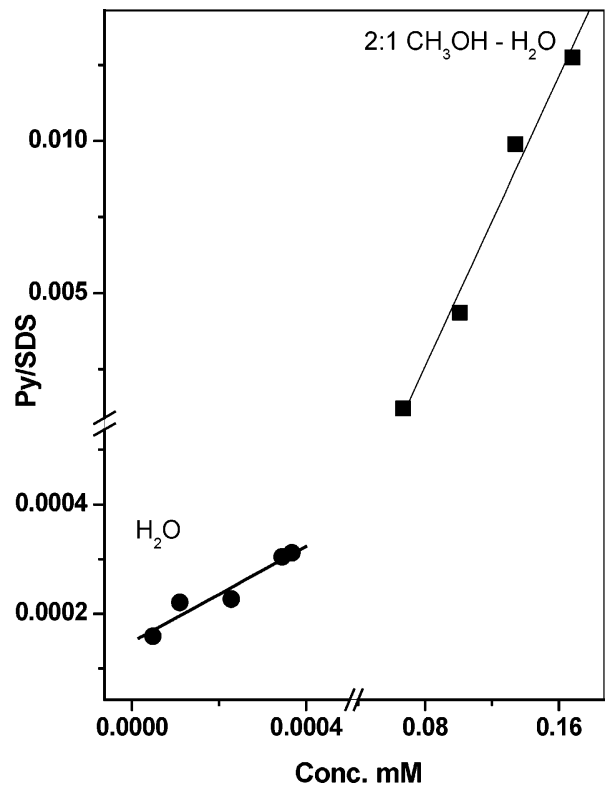

Figure 4. Adsorption isotherm of pyrene in Mg-Al LDH-DDS.

although not as intense, occur at the same position as the parent Mg-Al LDH-DDS.

Effect of solubilized pyrene on alkyl-chain conformation: The influence of the solubilized pyrene on the conformation of the methylene chains of the anchored bilayer was probed by vibrational spectroscopy. The infrared spectra of $\mathrm{Mg}-\mathrm{Al} \mathrm{LDH}-$ DDS with and without solubilized pyrene are similar (see the Supporting Information). In the infrared spectrum, bands due to the solubilzed pyrene are obscured by the surfactant bands; they are, however, seen in the Raman spectra and are discussed in a subsequent section.

The $\mathrm{C}-\mathrm{H}$ stretching region in the infrared spectrum of $\mathrm{Mg}$ Al LDH-DDS(Pyrene) is shown in Figure 2a. With an increase in the concentration of the solubilized pyrene, the methylene symmetric (sym $\mathrm{CH}_{2}$ ) and asymmetric, $\left(\right.$ asym $\left.\mathrm{CH}_{2}\right)$ stretching modes show a small shift $\left(\sim 3 \mathrm{~cm}^{-1}\right)$ to higher frequency with increasing concentration of the solubilized pyrene, indicating a marginal increase in conformational disorder. A similar behavior is observed in the Raman spectra in the $\mathrm{CH}_{2}$ stretching region of the pyrene solubilized bilayer shown in Figure $2 \mathrm{~b}$. The intensity ratio $\mathbf{I}_{2880} / \mathbf{I}_{2850}$, which is sensitive to chain conformation, shows a marginal decrease in value from 1.5 to 1.14 with 


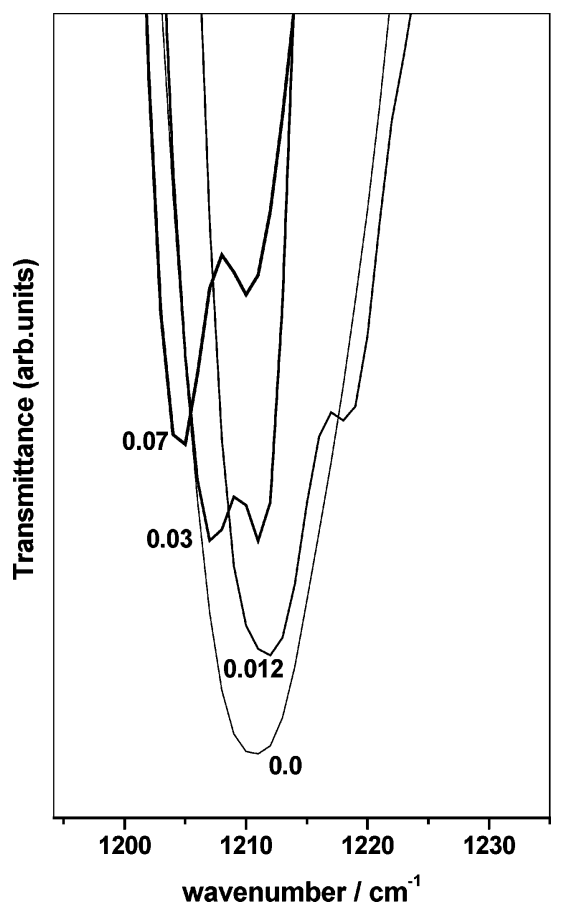

Figure 5. Sulfate stretching modes in the infrared spectra of $\mathrm{Mg}-\mathrm{Al}$ LDH-DDS(Pyrene) at different concentrations of the solubilized pyrene. The py/DDS values are indicated in the figure.

increasing pyrene content signifying a slight increase in chain disorder in the presence of pyrene. In addition to these changes the infrared active methylene scissoring mode that appears at $1474 \mathrm{~cm}^{-1}$ in $\mathrm{Mg}$-Al LDH-DDS is split into two bands, 1468 and $1476 \mathrm{~cm}^{-1}$, on solubilization of pyrene; the splitting of this mode is due to the lateral alkyl interchain interactions that are induced by pyrene on solubilization.

The most significant change seen in the vibrational spectra of the anchored bilayer in the presence of solubilized pyrene is in the infrared active sulfate headgroup bands (Figure 5). The $-\mathrm{O}-\mathrm{SO}_{3}$ headgroup in $\mathrm{Mg}-\mathrm{Al} \mathrm{LDH}-\mathrm{DDS}$ shows two bands, a symmetric stretch at $1083 \mathrm{~cm}^{-1}$ and an asymmetric stretching mode at $1213 \mathrm{~cm}^{-1}$. In the presence of pyrene the symmetric stretching mode is unaffected but the asymmetric stretch splits

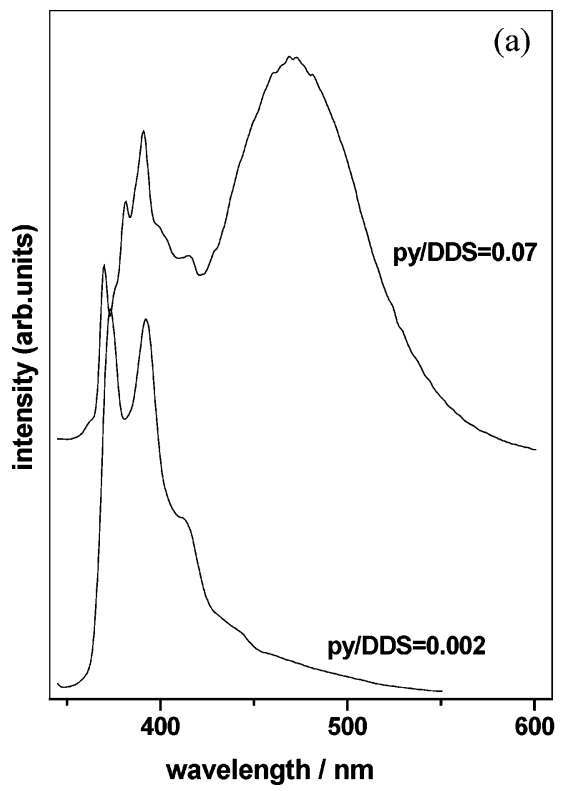

into two, 1204 and $1211 \mathrm{~cm}^{-1}$. These changes may be understood in the following way. The $\mathrm{O}-\mathrm{SO}_{3}$ group in the intercalated bilayer has $C_{3 v}$ symmetry provided the $-\mathrm{SO}_{3}$ group undergoes dynamic rotational disordering. The $-\mathrm{SO}_{3}$ has three S-O stretching vibrations: a totally symmetric vibration (1083 $\mathrm{cm}^{-1}$ ) and two asymmetric vibrations that are degenerate for a $-\mathrm{SO}_{3}$ group of at least $C_{3 v}$ symmetry. Symmetry lower than $C_{3 v}$ lifts the degeneracy associated with the asymmetric stretch and it appears split. The splitting of this mode in $\mathrm{Mg}-\mathrm{Al} \mathrm{LDH}-$ DDS when pyrene is present indicates loss of 3-fold symmetry. This would arise if the $-\mathrm{SO}_{3}$ groups were no longer rotationally mobile. This behavior is similar to the motional collapse of the $\mathrm{C}-\mathrm{H}$ methyl asymmetric stretching modes reported in $n$ alkanes. ${ }^{33}$ With increase in concentration of solubilized pyrene there is also a systematic red shift in the band positions of the $-\mathrm{SO}_{3}$ asymmetric stretching modes. The shift is believed to be influenced by the disorder in the intercalated chain. ${ }^{34}$ With increase in the solubilized pyrene content, the disorder of the intercalated surfactant chain increases leading to a progressive shift of the $-\mathrm{SO}_{3}$ group to lower wavenumbers.

Fluorescence spectra: The fluorescence emission and excitation spectra of Mg-Al LDH-DDS(Pyrene) at two different py/ DDS ratios 0.002 and 0.07 are shown in Figure 6. These ratios correspond to the lowest and highest concentration of included pyrene. The emission spectrum of Mg-Al LDH-DDS(Pyrene) at low concentrations shows only the monomer band while at higher concentrations both monomer and excimer emission are observed. The emission bands seen at 372, 384, 391, and 412 $\mathrm{nm}$ correspond to vibronic modes of the $\mathrm{S} 1-\mathrm{S} 0$ emission for an excitation of the $\mathrm{S} 0-\mathrm{S} 2$ transition $(340 \mathrm{~nm})$. The excimer band appears around $465 \mathrm{~nm}$. The excitation spectra, recorded by monitoring the emission at $391 \mathrm{~nm}$, show peaks at $341(0-$ 0 ) and $326 \mathrm{~nm}$ corresponding to the S0-S2 absorptions, 275 $(0-0)$ and $266 \mathrm{~nm}$ corresponding to the S0-S3 transitions, and 245 and $235(0-0) \mathrm{nm}$ corresponding to the S0-S4 absorptions (Figure 6). The excitation spectrum shows no change with concentration of the solubilized pyrene.

The polarity of the microenvironment within the anchored DDS bilayers of the Mg-Al LDH-DDS was established from the fluorescence spectra of pyrene included within the $\mathrm{Mg}-\mathrm{Al}$ LDH-DDS at low concentration. The fluorescence of pyrene

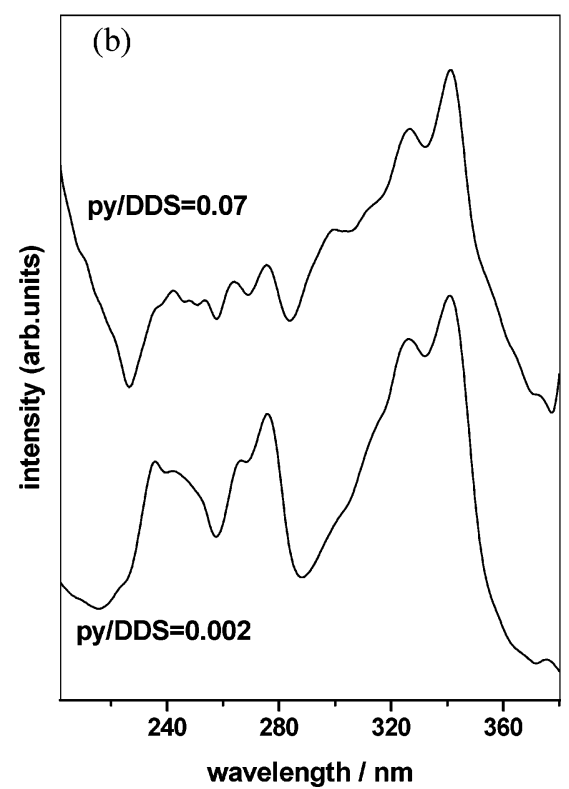

Figure 6. (a) Fluorescence emission of Mg-Al LDH-DDS(Pyrene) at low (py/DDS $=0.002)$ and high (py/DDS $=0.07)$ concentrations of solubilized pyrene for an excitation of $340 \mathrm{~nm}$ and (b) the corresponding excitation spectra recorded by monitoring emission at $390 \mathrm{~nm}$. 


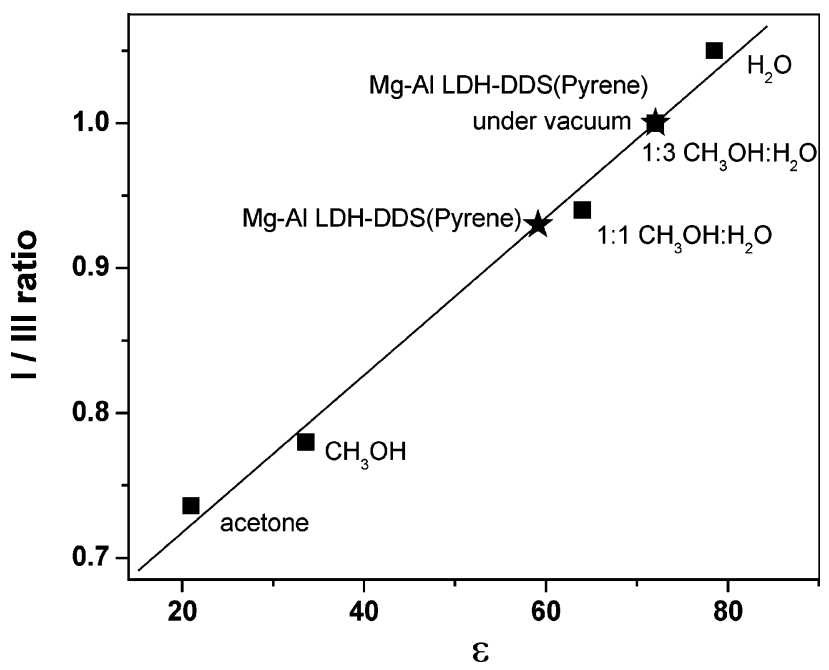

Figure 7. Variation of the fluorescence intensity ratio, $\mathbf{I}_{\mathrm{I}} / \mathbf{I}_{\mathrm{III}}$, as a function of solvent polarity. The values for Mg-Al LDH-DDS(Pyrene) $(\mathrm{py} / \mathrm{DDS}=0.07)$ are indicated

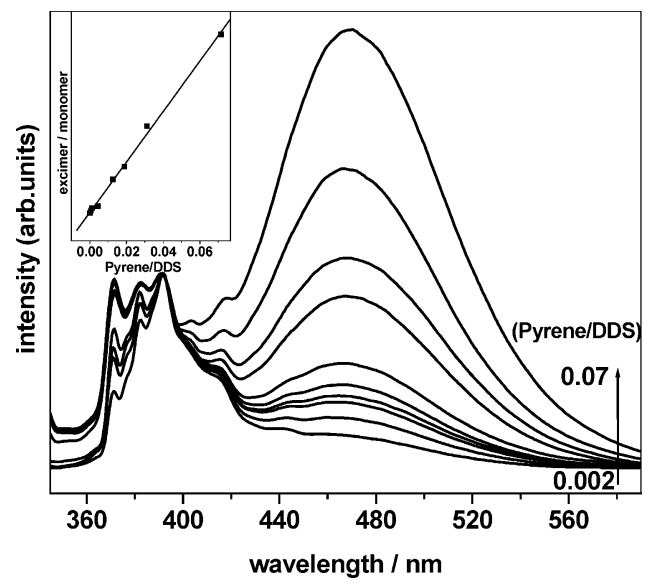

Figure 8. Fluorescence emission spectra of Mg-Al LDH-DDS(Pyrene) at different concentrations of the solubilized pyrene. The concentration ranges from a py/DDS value of 0.002 to 0.07 .

has been widely used to establish the polarity of the medium in which it is present. In polar solvents, there is an enhancement in the intensity of the $D_{2 h}$ symmetry forbidden $(0-0)$ band (Ham effect). ${ }^{35}$ The relative intensity of the first $\left(\mathbf{I}_{\mathrm{I}}\right)$ and third $\left(\mathbf{I}_{\mathrm{III}}\right)$ vibronic bands of the first singlet emission $(\mathrm{S} 1-\mathrm{S} 0)$ correlates reasonably well with solvent polarity. The $\mathbf{I}_{\mathrm{I}} / \mathbf{I}_{\mathrm{III}}$ intensity ratio of pyrene, $\mathbf{I}_{\mathrm{I}} / \mathbf{I}_{\mathrm{III}}$, varies, typically, from $\sim 0.6$ for pyrene in nonpolar solvents, like hexane, to 1.95 in polar solvents, like dimethyl sulfoxide. The $\mathbf{I}_{\mathrm{I}} / \mathbf{I}_{\mathrm{III}}$ intensity ratio for pyrene in the anchored bilayer has a value of 0.93 , suggesting that the polarity of the intercalated bilayer lies between that of a 1:3 methanolwater and a 1:1 methanol-water mixture (Figure 7).

This analysis is valid only in the absence of excimer formation. The presence of two pyrene molecules in close conjunction can effectively lower the symmetry making the symmetry-forbidden transitions allowed, and consequently, the $\mathbf{I}_{\mathrm{I}} / \mathbf{I}_{\mathrm{III}}$ ratio no longer reflects the polarity of the medium. It is for this reason that $\mathrm{Mg}$-Al LDH-DDS(Pyrene) at low concentration when excimer formation is absent was used to establish the polarity of the anchored bilayer.

The fluorescence emission spectra at different concentrations of pyrene solubilized in Mg-Al LDH-DDS are shown in Figure 8 . The excimer band $(465 \mathrm{~nm})$ intensity shoots up relative to the monomer with increase in pyrene concentration. The plot of excimer to monomer emission intensity ratio shows a linear increase with increasing py/DDS ratio (Figure 8 inset). This behavior is as expected for a situation where excimer formation is diffusion controlled and consequently, the probability of excimer formation would increase with increasing concentration of monomer. Figure 8 indicates that the pyrene molecules distributed in the anchored surfactant bilayer phase of $\mathrm{Mg}-\mathrm{Al}$ LDH-DDS have sufficient mobility to diffuse and interact with other pyrene molecules and form excimers.

Fluorescence lifetime measurements: The fluorescence decay of $\mathrm{Mg}-\mathrm{Al} \mathrm{LDH}-\mathrm{DDS}$ (Pyrene) at low concentrations (py/DDS $=0.002$ ), when excimer formation is absent, is shown in Figure 9a. The monomer decay was recorded at an excitation of 335 $\mathrm{nm}$ by monitoring emission at $390 \mathrm{~nm}$. The fluorescence decay from Mg-Al LDH-DDS(Pyrene) at higher py/DDS concentration (py/DDS $=0.07$ ) is shown in Figure 9b. At this concentration both monomer and excimer emissions are observed. The excimer decay was recorded with an excitation of $335 \mathrm{~nm}$ with emission monitored at $465 \mathrm{~nm}$. The excimer decay exhibits a rise time corresponding to the formation of the excimer from an excited monomer. The excimer and monomer decay curves were analyzed by using biexponential decay functions for both samples. The decay parameters are given in Table 1 . For the low py/DDS ratio samples the shorter component that was of the order of the prompt, $\sim 1 \mathrm{~ns}$, is due to scattering from the solid sample and was discarded (Figure 9a). No such component was observed for the py/DDS $=0.07$ sample. The excimer decay exhibits a rise-time (6.2 ns) with a negative exponential prefactor; this corresponds to the excimer formation time. It may be seen from Table 1 that this value is close to the shorter lifetime (9 ns) associated with monomer decay. This is consistent with classical Birks' kinetic scheme that requires biexponentials to fit both monomer and excimer decays with the lifetime associated with the negative exponential of the excimer decay being identical with one of the lifetimes associated with monomer decay. ${ }^{22}$

Effect of Evacuation: Disappearance of the Excimer. To determine the thermodynamic parameters associated with excimer formation the temperature variation of the fluorescence spectra of Mg-Al LDH-DDS(Pyrene) was investigated. The temperature-variation measurements required evacuation of the cryostat. It was found, however, that even on mild evacuation $\left(10^{-2}\right.$ Torr) the excimer bands disappeared (Figure 10) with a concomitant increase in the monomer emission. The effect was reversible; when the vacuum was released the excimer band reappeared. The disappearance and reappearance of the excimer band on evacuation and release of vacuum could be repeated any number of times without any loss of intensity. The fact that the excimer band reappears on release of vacuum clearly rules out loss of pyrene as the cause of the disappearance of the excimer band on evacuation. A possible clue to the origin of this phenomenon is the fact that the fluorescence intensity ratio $\left(\mathbf{I}_{\mathrm{I}} / \mathbf{I}_{\mathrm{III}}\right)$ of the low-concentration Mg-Al LDH-DDS(Pyrene) sample (py/DDS $=0.002$ ) goes from 0.93 to 0.99 on evacuation (Figure 7). This suggests that on evacuation pyrene molecules sample a less hydrophobic region of the intercalated bilayer. The disappearance of the excimer band on evacuation is probably due to the fact that when the solubilized pyrene moves into a less polar region of the anchored bilayer it lacks diffusion mobility and hence can no longer form excimers. There is no change in the interlayer spacing on evacuation and the X-ray diffraction pattern is identical with that shown in Figure 1. The present situation is different from the reported scenario for pyrene in the myristic acid functionalized LDH where removal 

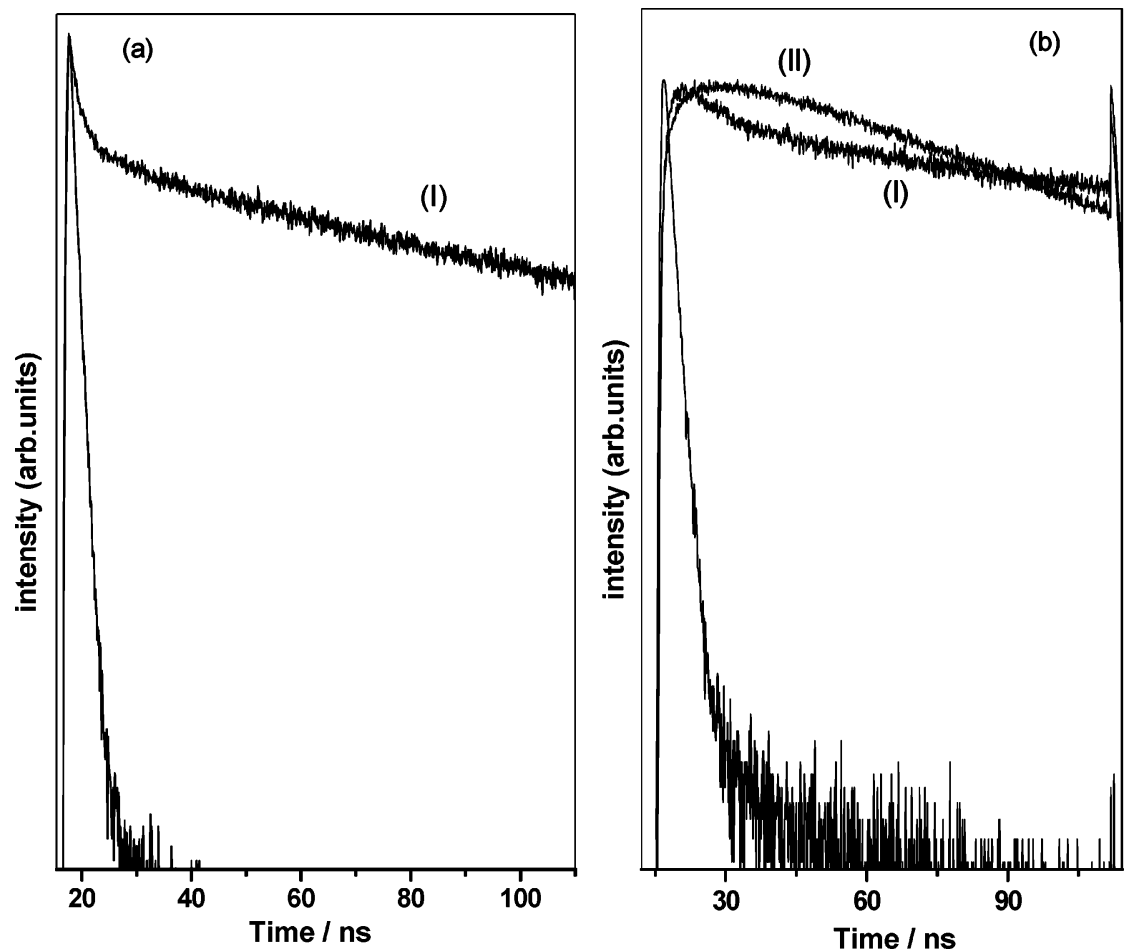

Figure 9. Monomer (I) and excimer (II) decay plots of Mg-Al LDH-DDS(Pyrene) (a) at low concentration of solubilized pyrene (py/DDS = $0.002)$ and $(b)$ at high concentration (py/DDS $=0.07)$ of solubilized pyrene.

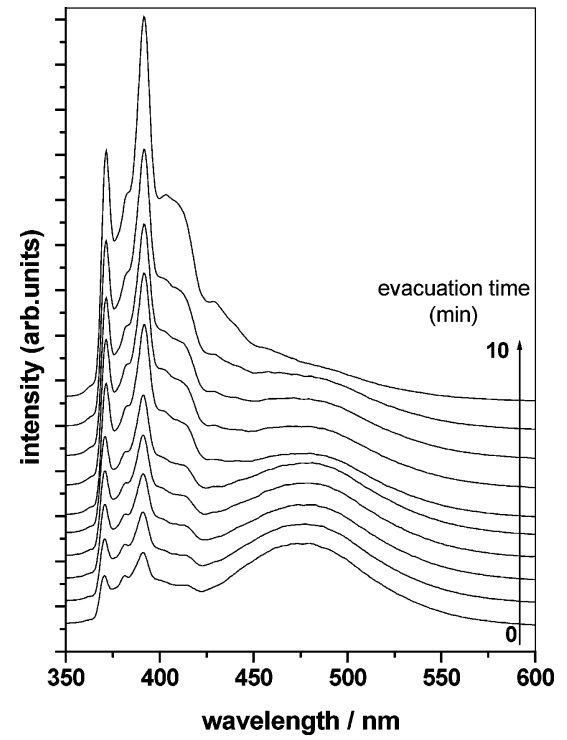

Figure 10. Fluorescence emission spectra of Mg-Al LDH-DDS(Pyrene) as a function of evacuation ( $10^{-2}$ Torr) time (in minutes).

TABLE 1: Decay Parameters (ns) of Mg-Al LDH-DDS(Pyrene)

\begin{tabular}{lll}
\hline Mg-Al LDH-DDS(Pyrene) & monomer & excimer \\
\hline low concn (py/DDS $=0.002)$ & 65 & \\
high concn (py/DDS $=0.07)$ & $9.0,115.3$ & $6.2,{ }^{a} 67.5$ \\
${ }^{a}$ Negative exponential prefactor. & &
\end{tabular}

of the solvent ethanol molecules leads to a doubling of the interlayer spacing. ${ }^{36}$

To understand why the pyrene molecules move to a less polar region on evacuation, thermogravimetry and the vibration spectra of the intercalated bilayer phase $\mathrm{Mg}-\mathrm{Al} \mathrm{LDH}$ DDS(Pyrene) on evacuation have been examined.

Thermogravimetry: Thermogravimetric (TG) and evolved water profiles for Mg-Al LDH-DDS(Pyrene) in flowing $\mathrm{N}_{2}$ and
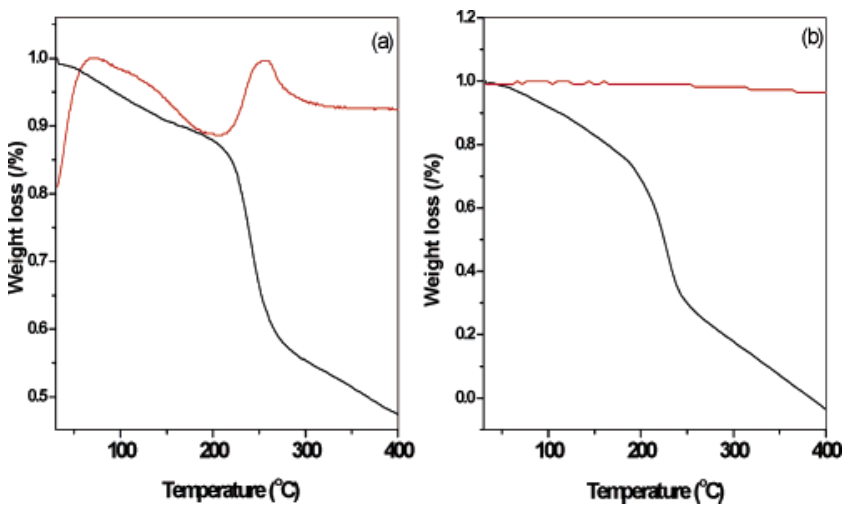

Figure 11. TG (black line) and evolved water $(\mathrm{m} / \mathrm{e}$ 18) profile (red line) of Mg-Al LDH-DDS(Pyrene) (a) in air and (b) in a vacuum.

under vacuum are shown in Figure 11. In the as-prepared $\mathrm{Mg}$ Al LDH-DDS(Pyrene) sample the weight loss at $\sim 250{ }^{\circ} \mathrm{C}$ due to the decomposition of the compound is associated with the desorption of water, as may be seen from the evolved water profile (Figure 11a). In the sample that had been evacuated no such water evolution is associated with the decomposition at $\sim 250^{\circ} \mathrm{C}$. It is clear from the TG measurements that the effect of evacuation is the removal of water from $\mathrm{Mg}-\mathrm{Al} \mathrm{LDH}$ DDS(Pyrene).

Vibrational spectra on evacuation: It is clear from the TG analysis that the disappearance of the excimer band on evacuation is a consequence of the loss of water of hydration probably associated with the sulfate headgroup of the alkyl chain of the bilayer. When water molecules are removed the pyrene molecules move to a region of the bilayer where they are no longer mobile and hence excimer formation is absent. To identify the location of the solubilized pyrene in the bilayer the IR and Raman spectra of Mg-Al LDH-DDS(Pyrene) were recorded under vacuum.

The infrared spectra of Mg-Al LDH-DDS(Pyrene) do not show any significant change on evacuation. It is difficult to 


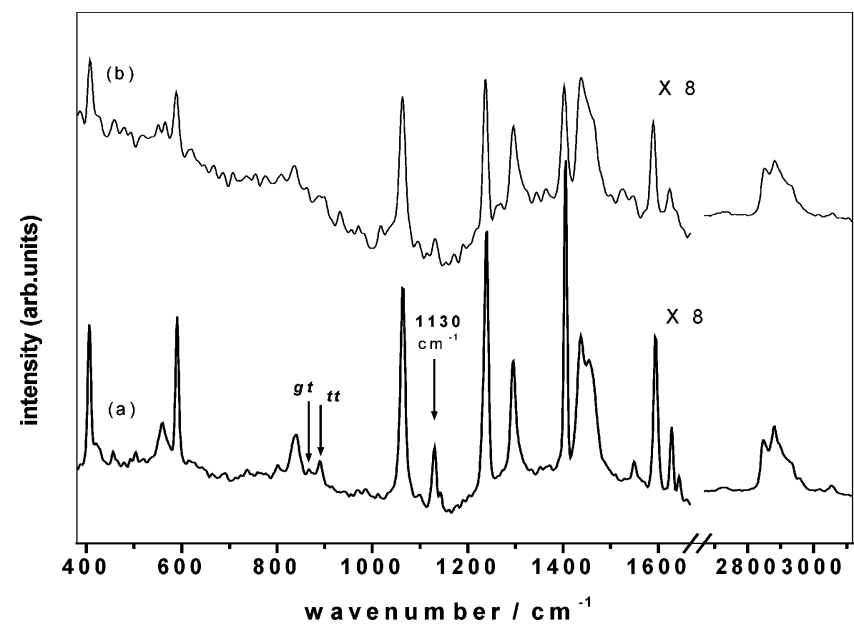

Figure 12. Raman spectra of (a) as-prepared Mg-Al LDH-DDS(Pyrene) and (b) on evacuation.

identify water bands in the infrared because of the presence of the hydroxyl modes of the LDH layers. Loss of water, presumably water of hydration of the sulfate headgroup, does not affect the sulfate vibrational modes; they remain split. The vibrational modes associated with the "guest" pyrene and the "host" surfactant alkyl chain are seen in the Raman spectra and the effect of evacuation on both these modes is examined. The Raman spectra of Mg-Al LDH-DDS(Pyrene) before and after evacuation are shown in Figure 12. The spectra have been normalized with respect to the integrated intensity in the methylstretching region $\left(3000-2800 \mathrm{~cm}^{-1}\right)$ to allow for a direct comparison of Raman mode intensities in the two spectra.

Pyrene Raman modes: Bands characteristic of pyrene are well resolved in the Raman spectra of Mg-Al LDH-DDS(Pyrene) (Figure 12). The $\mathrm{C}-\mathrm{H}$ symmetric stretching modes of the solubilized pyrene appear as weak bands at 3020 and $3053 \mathrm{~cm}^{-1}$. The relatively stronger bands of pyrene appear in the region $1200-1650 \mathrm{~cm}^{-1}$. The pyrene ring vibrations appear at 1628 , 1594,1454 , and $1437 \mathrm{~cm}^{-1}$, the $\mathrm{C}-\mathrm{C}$ stretching modes occur at 1405 and $1240 \mathrm{~cm}^{-1}$, while the out-of-plane ring deformation and $\mathrm{C}-\mathrm{C}-\mathrm{C}$ in-plane bending occurs at 590 and $405 \mathrm{~cm}^{-1}$, respectively.

An expanded view of the Raman spectra of Mg-Al LDHDDS(Pyrene) in the region $1210-1640 \mathrm{~cm}^{-1}$, where characteristic pyrene bands appear, is shown in Figure 13. On evacuation, the pyrene modes are blue shifted by $2-7 \mathrm{~cm}^{-1}$. The pyrene ring vibrations at 1628 and $1594 \mathrm{~cm}^{-1}$ shift to 1623 and $1589 \mathrm{~cm}^{-1}$ respectively, while the $\mathrm{C}-\mathrm{C}$ stretching modes at 1405 and $1240 \mathrm{~cm}^{-1}$ shift to 1402 and $1237 \mathrm{~cm}^{-1}$ and the out-of-plane ring deformation at $590 \mathrm{~cm}^{-1}$ shifts to $589 \mathrm{~cm}^{-1}$ on evacuation. It is known that pyrene vibrational modes are red shifted on association. ${ }^{37}$ The observed blue shift indicates the absence of association between solubilized pyrene molecules in the anchored bilayer on evacuation. The results are in agreement with the fluorescence spectra, which showed the disappearance of excimer bands on evacuation; association of an excited monomer and a ground-state monomer is a prerequisite for excimer formation.

Surfactant Raman bands: No change in the methylenestretching region $\left(3000-2800 \mathrm{~cm}^{-1}\right.$ ) in the Raman spectra of Mg-Al LDH-DDS(Pyrene) was observed on evacuation. The conformation sensitive $\mathbf{I}_{2880} / \mathbf{I}_{2850}$ intensity ratio, too, does not change on evacuation. This ratio as well as the position of the methylene symmetric and asymmetric modes are, however, not too sensitive to a small population of gauche defects. Modes that arise from coupling of trans methylene units, e.g., the

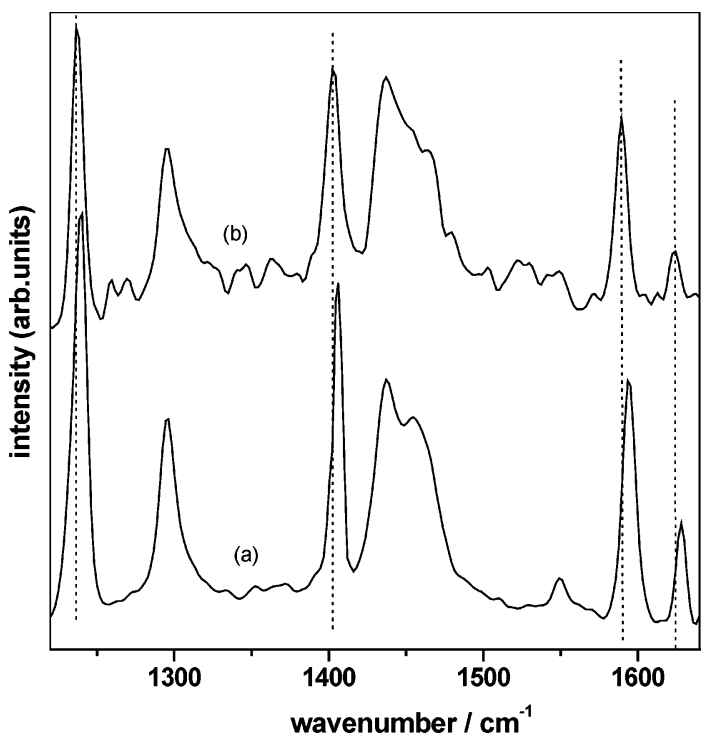

Figure 13. Raman spectra of (a) as-prepared Mg-Al LDH-DDS(Pyrene) (py/DDS $=0.07$ ) in the region $1210-1640 \mathrm{~cm}^{-1}$ and (b) spectra recorded under vacuum.

Raman C-C skeletal stretch at $1130 \mathrm{~cm}^{-1}$, would, however, be more sensitive to small concentrations of gauche disorder. The presence of a single gauche conformer in an otherwise alltrans chain or segment would effectively decouple these modes and such chains would no longer contribute to the intensity of these bands. The band at $1130 \mathrm{~cm}^{-1}$ in the Raman spectrum is associated with the in-phase $\mathrm{C}-\mathrm{C}$ stretching mode of an alltrans segment of the hydrocarbon chain and is known to undergo a reduction in intensity upon introduction of gauche bonds. ${ }^{38}$ However, as shown by Pink et al. ${ }^{39}$ and experimentally verified by Snyder et al. ${ }^{40}$ the intensity of the $1130 \mathrm{~cm}^{-1}$ band is heavily weighted by conformers having extended all-trans segments. In the model of Pink et al., coupling of the $\mathrm{C}-\mathrm{C}$ stretching vibration of two trans segments separated by a gauche bond is taken into account. The gauche bond causes the trans segments to vibrate out of phase, and consequently, the intensity decrease per gauche bond is amplified even at low gauche concentrations. Thus, the contribution of conformers having a single gauche bond at the end of the chain to the intensity of the $1130 \mathrm{~cm}^{-1}$ band is half that of an all-trans chain, whereas the presence of a single gauche bond at any other position decreases the contribution of such conformers to less than $20 \%$. In the pyrenesolubilized Mg-Al LDH-DDS it may be seen from Figure 11 that the intensity of the $1130 \mathrm{~cm}^{-1}$ band drops quite significantly on evacuation; the normalized intensity ratio drops from 1.0 to 0.44 on evacuation.

The results indicate that the movement of solubilized pyrene on evacuation induces disorder in the alkyl chain of the bilayer. To identify the nature and location of the gauche defects the Raman modes characteristic of chain-end disorder were examined in detail. Raman modes sensitive to chain-end disorder appear in the frequency region $900-830 \mathrm{~cm}^{-1}$ that is free of interfering spectral features. These bands are associated with specific localized modes at the end of the $n$-alkane chain and involve primarily methyl rocking and $\mathrm{C}-\mathrm{C}$ stretching coordinates and are usually referred to as the methyl rocking modes. ${ }^{41}$ The frequency of each of these modes is determined by the conformation at the end of a chain that is otherwise all-trans. Separate Raman bands are observed for $t t\left(890 \mathrm{~cm}^{-1}\right)$, gt $(875$ $\left.\mathrm{cm}^{-1}\right), g g\left(862 \mathrm{~cm}^{-1}\right)$, and $\mathrm{tg}\left(846 \mathrm{~cm}^{-1}\right)$ chain end conformers. ${ }^{41}$ Bands corresponding to these modes are reasonably intense in the Raman spectra and have been used to study disorder in 


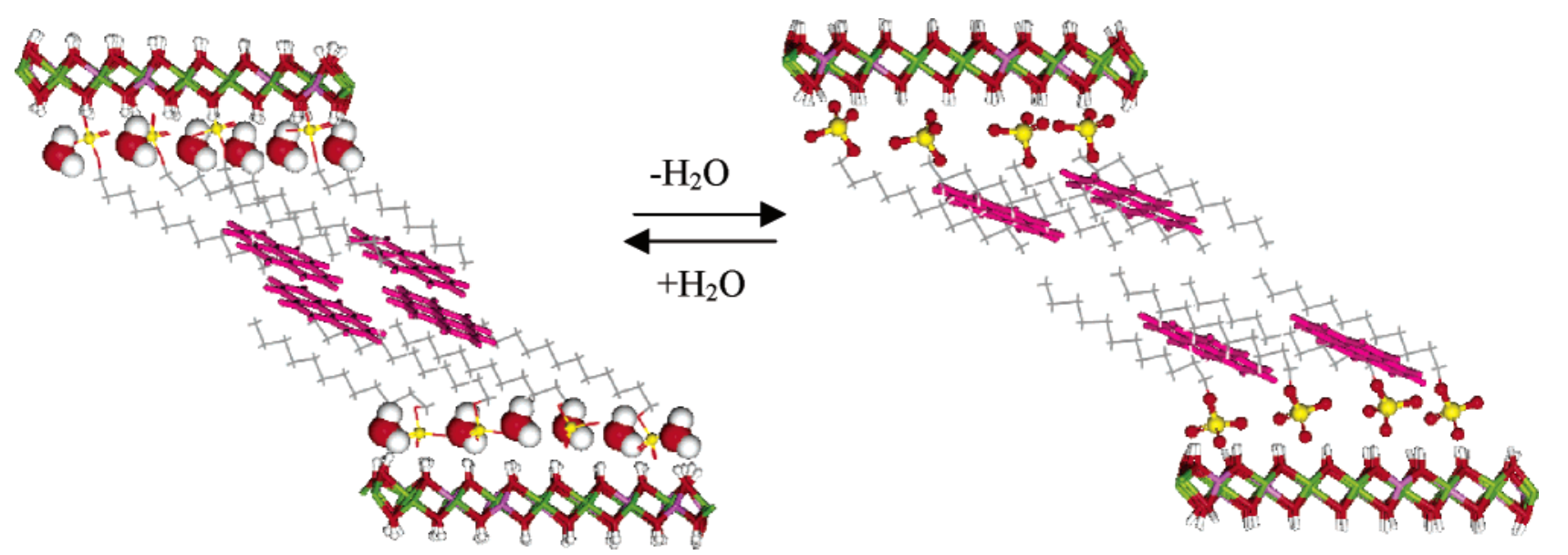

Figure 14. Location of pyrene in the anchored surfactant bilayer phase Mg-Al LDH-DDS

crystalline $n$-alkanes. ${ }^{42}$ The alkyl chain-end Raman mode at 890 $\mathrm{cm}^{-1}$ that is characteristic of the $t-t$ conformation is clearly seen in the Raman spectra of the as-prepared Mg-Al LDHDDS(Pyrene) but on evacuation this band is almost absent. The band due to the end-chain $g-t$ conformation at $875 \mathrm{~cm}^{-1}$ is seen as a weak band in the as-prepared $\mathrm{Mg}$-Al LDHDDS(Pyrene) but is absent on evacuation. The results suggest that on evacuation the solubilized pyrene molecules move into the interior of the bilayer and as a consequence increased free space is available at the chain termini allowing for end-chain disorder.

Location of pyrene in the anchored bilayer: From the diffraction and spectroscopic measurements it is possible to construct a model for the location of pyrene in the anchored bilayer. In the as-prepared $\mathrm{Mg}-\mathrm{Al} \mathrm{LDH}-\mathrm{DDS}$ (Pyrene) the $-\mathrm{SO}_{4}$ headgroup is hydrated and the pyrene molecules would, therefore, be located as far as possible from the head where the bilayer is least polar. Two possible locations are at the chain ends or in the gap between the alkyl chains of the bilayer. The latter may be ruled out since solubilization would then result in an expansion of the interlayer distance, which is not observed in the X-ray diffraction. The possible location is therefore near the chain termini as shown in the left of Figure 14. In this location the pyrene molecules are partially associated and excimer formation requires only a minimum change in orientation/displacements. The latter is reflected in the short rise time associated with excimer formation in the time-resolved fluorescence measurements. The presence of pyrene in the anchored bilayer inhibits the rotational disordering motion of the sulfate headgroup of the surfactant.

On evacuation the water molecules hydrating the headgroup are removed. The chain termini are no longer the least polar regions of the bilayer. The pyrene molecules now move into the interior of the bilayer, which is less polar, but at the cost of loss of mobility (Figure 14). The loss of mobility is reflected in the absence of excimer formation in the fluorescence spectra. The presence of the pyrene in the interior of the bilayer probably causes the alkyl chains to splay allowing for large free space for the chain termini and hence end-chain disorder. The increased end-chain disorder is seen as loss in intensity of the methyl-rocking mode of the ordered end chain $t-t$ conformer in the Raman spectra.

\section{Conclusions}

The anionic clay, Mg-Al LDH, has been functionalized by anchoring the anionic surfactant, dodecyl sulfate, ions to the gallery walls. Dodecyl sulfate ions are confined within the galleries of LDH by a simple ion-exchange intercalation reaction to give $\mathrm{Mg}_{0.63} \mathrm{Al}_{0.37}(\mathrm{OH})_{2}(\mathrm{DDS})_{0.37}$. Intercalation occurs with an expansion of $21.4 \AA$, which indicates that within the galleries of the LDH the methylene chains are arranged as a normal bilayer with a tilt angle of $58^{\circ}$. Vibrational spectroscopy indicates the intercalated methylene chains adopt an almost alltrans conformation. Pyrene molecules have been solubilized in the anchored bilayer phase of $\mathrm{Mg}-\mathrm{Al} \mathrm{LDH}-\mathrm{DDS}$ by partitioning from a polar solvent. Pyrene molecules induce conformational disorder in the intercalated alkyl chains and more importantly reduce the rotational disordering motion of the sulfate headgroup of the surfactant. The fluorescence spectra of pyrene indicate formation of excimers whose intensity increases at higher concentrations of the solubilized pyrene. The pyrene-solubilized Mg-Al LDH-DDS(Pyrene) exhibits an unusual phenomena; on evacuation the excimer band disappears but reappears on releasing vacuum. It is shown that this behavior arises due to the loss of water of hydration of the headgroup on evacuation and as a consequence the pyrene moves into the less polar interior of the bilayer where it is immobile and can no longer diffuse and form excimers. The motion of pyrene into the interior of the bilayer creates free space near the surfactant chain termini, which manifests in the appearance of the methyl-rocking mode of the ordered $(t-t)$ end-chain conformers in the Raman spectra.

Supporting Information Available: Infrared and Raman spectra of Mg-Al LDH-DDS, infrared and Raman spectra of Mg-Al LDH-DDS(Pyrene) (py/DDS $=0.07)$, infrared and Raman table of spectral assignments for Mg-Al LDH-DDS and Mg-Al LDH-DDS(Pyrene), and Raman spectra of pyrene/SDS physical mixtures at different molar ratios and plot of $\mathbf{I}_{1240} /$ $\mathbf{I}_{\mathrm{CH}_{2}}$ as a function of the pyrene/SDS ratio. This material is available free of charge via the Internet at http://pubs.acs.org.

\section{References and Notes}

(1) Williams, S.; Becerro, A. I.; Castro, M. A.; Thomas, R. K. Phys. $B$ 1997, 234-236, 1096.

(2) Holsen, T. M.; Taylor, E. R.; Seo, Y. C.; Anderson, P. R. Environ. Sci. Technol. 1991, 25, 1585.

(3) Lagaly, G. Angew. Chem., Int. Ed. Engl. 1976, 15, 575.

(4) Venkataraman, N. V.; Vasudevan, S. J. Phys. Chem. B 2003, 107, 10119.

(5) Drits, V. A.; Sokolova, T. N.; Sokolova, G. V.; Cherkashin, V. I. Clays Clay Miner. 1987, 35, 401.

(6) de Roy, A.; Forano, C.; El Malki, K.; Besse, J. P. In Expanded Clays and other microporous solids; Rinhold: New York, 1992; Vol. 2, pp 108-69. 
(7) de Roy, A.; Forano, C.; Besse, J. P. In Layered Double Hydroxides: Present and Future; Rives, V., Ed.; Nova Science: New York, 2001; pp $1-37$.

(8) Venkataraman, N. V.; Vasudevan, S. J. Phys. Chem. B 2003, 107, 5371. 1961.

(9) Zhao, H.; Vance, G. F. J. Chem. Soc., Dalton. Trans. 1997, 11,

(10) Mohanambe, L.; Vasudevan, S. Inorg. Chem. 2005, 44, 2128.

(11) Mohanambe, L.; Vasudevan, S. J. Phys. Chem. B 2005, 109, 22523.

(12) Mohanambe, L.; Vasudevan, S. J. Phys. Chem. B 2005, 109, 11865.

(13) Ahuja, R. C.; Mobius, D. Langmuir 1992, 8, 1136.

(14) Kalyanasundaram, K.; Thomas, J. K. J. J. Am. Chem. Soc. 1977, 99, 2039.

(15) Cao, T.; Munk, P.; Ramireddy, C.; Tuzar, Z.; Webber, S. Macromolecules 1991, 24, 6300.

(16) Lochmuller, C. H.; Wenzel, T. J. Macromolecules 1991, 24, 6300.

(17) In Photochemistry in Organized and Constrained Media; Ramamurthy, V., Ed.; VCH Publishers: New York, 1991.

(18) Ramamurthy, V.; Casper, J. V.; Eaton, D. F.; Kuo, E. W.; Corbin, D. R. J. Am. Chem. Soc. 1992, 114, 3882.

(19) Kaufman V. R.; Avnir, D. Langmuir 1986, 2, 717.

(20) Bohorquez, M.; Patterson, L. K. Langmuir 1990, 6, 1739

(21) Radha, A. V.; Kamath, P. V.; Shivakumara, C. Solid State Sci. 2005, 7, 1180 .

(22) Birks, J. B. In Photophysics of Aromatic molecules; John-Wiley and Sons: New York, 1970.

(23) Nakajima, A. Bull. Chem. Soc. Jpn. 1971, 44, 3272.

(24) Kopka, H.; Beneke, K.; Lagaly, G. J. Colloid Interface Sci. 1988, 123,2

(25) Wallach, D. F. H.; Verma, S. P.; Fookson, J. Biochim. Biophys. Acta 1979, 559, 153 and references therein.
(26) Levin, I. L. In Advances in Infrared and Raman Spectroscopy; Wiley-Heyden: New York, 1984; pp 1-48.

(27) Venkataraman, N. V.; Mohanambe, L.; Vasudevan, S. J. Mater. Chem. 2003, 13, 170.

(28) MacPhail, R. A.; Strauss, H. L.; Snyder R. G.; Elliger, C. A. J. Phys. Chem. 1984, 88, 334.

(29) Snyder, R. G.; Strauss, H. L.; Elliger, C. A. J. Phys. Chem. 1982, 86,5145 .

(30) Snyder, R. G.; Scherer, J. R. J. Chem. Phys. 1979, 71, 3221.

(31) Snyder, R. G.; Scherer, J. R.; Gaber, B. P. Biochim. Biophys. Acta 1980, 601, 47.

(32) Cary, T. C.; Louis, J. P.; Virgil, H. F. Science 1979, 206, 831.

(33) MacPhail, R. A.; Snyder, R. G.; Strauss, H. L. J. Chem. Phys. 1982, $77,1118$.

(34) Scheuing, D. R.; Weers, J. G. Colloids Surf. 1991, 55, 41.

(35) (a) Koyanagi, M. J. Mol. Spectrosc. 1968, 25, 273. (b) Robinson, G.W. J. Chem. Phys. 1967, 46, 572.

(36) Dutta, P. K.; Robins, D. S. Langmuir 1994, 10, 4681.

(37) Bree, A.; Kydd, R. A.; Misra, T. N.; Vilkos, V. V. B. Spectrochim. Acta 1971, 27A, 2315.

(38) Gaber, B. P.; Peticolas, W. L. Biochim. Biophys. Acta 1977, 465 260.

(39) Pink, D. A.; Green, T. J.; Chapmann, D. Biochemistry 1980, 19, 349.

(40) Snyder, R. G.; Cameron, D. G.; Casal, H. L.; Compton, D.; Mantsch H. H. Biochim. Biophys. Acta 1982, 684, 111

(41) Kim, Y.; Strauss, H. L.; Snyder, R. G. J. Chem. Phys. 1989, 93, 485 .

(42) Maissara, M.; Devaure, J. J. Raman Spectrosc. 1987, 18, 181. 